\title{
Algunas recomendaciones en la práctica de la anatomía patológica
}

\author{
Recommendations for pathological anatomy practice
}

\author{
M Alfonso Valenzuela Espinoza*
}

La enorme brecha que existe entre la instrucción y la práctica de la medicina a ninguno pasa inadvertida, desde luego no pretendemos abordar las circunstancias particulares en las que sucede este fenómeno, sino meramente señalar que tal vez el entusiasmo académico que nos conduce a abarcar el máximo de conceptos en la formación académica de la anatomía patológica, poco ayuda al facultativo en la práctica profesional.

Esto se manifiesta sobre todo en la presentación de los casos, pues la correlación clinicopatológica de los mismos es mínima por no decir nula, lo que resulta en un análisis pobre de los conceptos básicos fisiopatológicos de cualquier enfermedad. Parte de la razón por la cual los médicos no proveen información adecuada se basa en el malentendido de que los hallazgos anatomopatológicos son específicos y característicos en toda instancia.

La praxis de la anatomía patológica exige por razones obvias, un rigor científico de métodos, que cada vez más se pierde en la mediocre pretensión de emitir diagnósticos reducidos a la distinción de malignidad o benignidad, como si se tratara de una simple diferenciación entre lo blanco y lo negro. Parecería entonces, que nuestra labor se ha visto encaminada a establecer única y exclusivamente esa distinción, cuando la realidad precisa es que el diagnóstico encierra un sin fin de matices, para mencionar un supuesto, existen lesiones con hallazgos histológicos similares que presentan comportamiento biológico diferente y que la sola determinación de benignidad o malignidad no explicaría la entidad.

Para ello es prudente mencionar ejemplos, tal como ocurre con lesiones donde proliferan células gigantes (osteoclastos), las cuales se presentan asociadas con el hiperparatiroidismo, así como en los tumores de células gigantes óseos. En la primera enfermedad la paratohormona participa en la proliferación de osteoclastos, los cuales lo hacen de manera reactiva, mientras que en el tumor de células gigantes dichas células proliferan de manera autónoma y sin control, lo que explica su naturaleza neoplásica, en el segundo ejemplo se encuentran granulomas, los cuales se presentan en diferentes enfermedades infecciosas, neoplásicas y autoinmunes, las que tienen etiopatogenias disímbolas y que comparten la presencia de los granulomas como denominador común.

Estos ejemplos justifican plenamente que los hallazgos morfológicos deben ser analizados con los datos clínicos, estudios de imagen y resultados de laboratorio. Existe una clara oposición a que continúe aquella práctica, es menester que en el ejercicio de nuestra labor rompamos los paradigmas en la emisión del diagnóstico y busquemos alternativas. La determinación colegiada, que es la participación de los diferentes médicos en la solución del problema, es una opción que permitirá profundidad en la elaboración y determinación del diagnóstico, pero sobre todo, lo dotará de confiabilidad que se traducirá en el ofrecimiento de mejores tratamientos a los pacientes.

\footnotetext{
* Médico Anatomopatólogo. Jefe del Servicio de Anatomía Patológica, Hospital General de Tijuana Baja California.
}

Este artículo puede ser consultado en versión completa en http://www.medigraphic.com/facultadodontologiaunam 